\title{
THE PATTERN OF OLFACTORY INNERVATION
}

BY

\author{
W. E. LE GROS CLARK and R. T. TURNER WARWICK \\ From the Department of Anatomy, University of Oxford
}

(RECEIVEd 31st July, 1946)

IT is desirable that, from time to time, commonly accepted statements regarding anatomical pathways and connexions in the peripheral and central nervous systems should be carefully reviewed in the light of modern technical methods of investigation, for it must be admitted that not a few of these statements are based on old methods which are now recognized to be too crude to permit of really accurate conclusions. In recent years, indeed, a number of apparently well-established facts have been shown by critical studies to be erroneous. For example, the so-called ventral nucleus of the lateral geniculate body and the pulvinar are no longer accepted as terminal stations of the optic tract, and the striæ acousticæ have been shown to be unconnected with the auditory system. Of all the systems in the brain which call for a careful revision, that related to olfaction seems most urgently in need of treatment. The complexities of the rhinencephalon, as they are expounded in most text-books, are largely based on the accounts of early investigators who had to rely for their conclusions on the examination of Weigert sections of normal material or of Marchi preparations-methods which, as is now well recognized, are both highly unreliable by themselves even for fibre connexions of an apparently simple and direct kind. There is reason to think, indeed, that some components of the so-called rhinencephalon should be excluded altogether from this system. Thus, there is now grave doubt whether the hippocampus (together with its direct and indirect connexions, such as the mamillary body and the anterior nucleus of the thalamus) can in any way be said to be primarily concerned with smell.

In view of these uncertainties, it was decided to investigate anew the olfactory connexions of the brain, and in this paper we are concerned with the pattern of innervation of the olfactory mucosa, and with the projection of the latter on the olfactory bulb. Our main intention was to approach these problems by studying the retrograde degeneration in the olfactory epithelium which follows partial or total destruction of the olfactory bulb. In the course of the investigation, material was also obtained which permitted certain observations to be made on the olfactory receptors, on the cytological details of their retrograde degeneration, and on the intranasal course of the olfactory nerves.
Most of the observations recorded in this paper were made on rabbit material. The fixation of the olfactory mucosa presented considerable difficulty. The method finally selected, because it gave the best results with protargol and was also adequate for the other stains employed, was perfusion of 70 per cent. alcohol through the aorta, after preliminary washing through with normal saline, as recommended by Bodian (1936). Another unexpected difficulty arose from the fact that a large number of laboratory rabbits suffer from a chronic rhinitis which leads to gross pathological changes in the olfactory mucosa. Consequently, a considerable proportion of our material, experimental and otherwise, had to be discarded as useless. In the latter part of our investigation, rabbits a few weeks old were used in order to avoid this difficulty, but experimental lesions in them were found to be more susceptible to infection.

In the histological study of the olfactory epithelium in rabbits the septal mucosa was always used, since in these animals the greater part of the nasal septum is cartilaginous and thus does not require decalcification. However, certain of our observations were confirmed on mice in which the whole of the nasal cavity was sectioned for histological study after decalcification with 5 per cent. nitric acid and staining with a modification of Bielschowsky's method. From the rabbit material, paraffin sections were prepared and stained by Bodian's protargol method, hæmatoxylin and eosin, or methylene blue.

The experimental lesions in the olfactory bulb were made by the exposure (under nembutal anæsthesia and with strict aseptic technique) of the olfactory bulb and the frontal pole of the cerebral hemisphere. Total or partial removal of the bulb was then effected by cutting through the bulb or its peduncle with a fine-bladed scalpel (care being taken not to injure the underlying dura mater which covers the cribriform plate of the ethmoid), and gently scooping out the detached portion. Hæmorrhage was usually very slight, and was easily controlled by pressure with a pledget of cotton wool. In most cases, the animals made a rapid and uneventful recovery from the operation.

\section{The Olfactory Receptors in the Rabbit}

The olfactory sensory cells of mammals have been described by a number of histologists (e.g. Exner, 1872; von Brunn, 1875, 1892; Cajal, 1889; Grassi and Castronuovo, 1889; van Gehuchten, 1890; Kallius, 1905; Read, 1908; van der Stricht, 1909; Alcock, 1910; Kolmer, 1927), and it is now well recognized that each consists of a small cell-body 
with a round nucleus embedded in a minimal amount of cytoplasm, an exceedingly fine proximal process (which is continued as an olfactory nerve fibre), and a coarser peripheral process. The latter terminates at the surface in a small thickening which gives rise to very fine olfactory hairs. In the course of our experimental studies, we have had occasion to examine many protargol preparations of the normal olfactory mucosa of the rabbit, in which the peripheral processes of the sensory cells are displayed with unusual clarity. Their appearance in these sections suggests that current descriptions of the olfactory receptors of mammals may require some revision, and it is for this reason that the following brief description is given.

For convenience of terminology, the main part of the peripheral process is here called the "olfactory rod", and the thickening of its free end is called the "terminal swelling". The olfactory rods vary in length from $20 \mu$ to $90 \mu$. In the greater part of their length, their diameter is slightly uneven and measures $0 \cdot 6-1 \cdot 5 \mu$. They stain deeply with protargol and can be seen to have a neurofibrillar structure. Throughout most of their length the neurofibrillæ are disposed peripherally so that the rods (particularly if viewed in cross-section) have a "tubular" appearance. Proximally the neurofibrillæ fan out into the meagre cytoplasm of the cell body. Distally they become more compactly arranged as they pass into the terminal swelling, and here the olfactory rod is constricted to a thickness of $0 \cdot 3-0 \cdot 6 \mu$.

Some doubt has been expressed (for example, by von Brunn, 1892) whether the terminal swellings of the olfactory rods are normal structures or whether they are post-mortem artifacts. But, as Kallius (1905) observes, if they are not present in life they must be formed extraordinarily quickly after death since they are always to be seen even in freshly fixed animal material (though, according to the same author, they appear smaller in osmic acid preparations than in preparations fixed in Müller's solution). In successful impregnations in our own material, the terminal swellings are regularly developed at the distal end of all the olfactory rods. They show a variation in size, but in general appear relatively somewhat larger than they are commonly depicted to be in text-book figures. Van der Stricht (1909) has given the name "olfactory vesicle" to the terminal swelling, but it does not appear to be vesicular in the usually accepted sense of the term. Rather, the swelling forms a cup-shaped hollow which narrows down to a circular margin from which the olfactory hairs splay out in a stellate arrangement, the whole formation bearing a close resemblance to the gamopetalous corolla of a campanulate or urceolate flower with the free portions of the petals slender and pointed (Pl. I, Fig. 1).

The olfactory hairs are short, straight, or slightly curved processes, $1-2 \mu$ in length and about $0 \cdot 1 \mu$ in width, and in each sensory element they are remarkably even both in length and width. They end abruptly in blunt tips, and in some cases the latter may even appear to be a little thickened (Figs. 1 and 3). Moreover, the hairs radiate out in a single series from the peripheral part of the terminal swelling, their attached ends forming a single ring; they do not project as spinous processes from all parts of the swelling as sometimes portrayed in diagrams. This latter appearance is probably based on the examination of abnormal sensory cells.

In some of our sections, the appearance and disposition of the olfactory hairs show rather marked variations. Thus there may be a single stout process projecting straight up into the overlying layer of mucus, sometimes terminating in a sharp point or in a minute vesicle (Fig. 5). In other cases, one or more of the hairs may end in darkly staining end-bulbs of irregular size (Fig. 4), or the hairs may be clumped together (Fig. 2). Sometimes, again, the hairs appear to be prolonged into long and exceedingly fine filaments which eventually pass beyond the range of visibility as they are traced in the film of mucus covering the epithelium. In this connexion it may be noted that, in 1901, Jagodowski described such filaments (or " flagella" as he termed them) in the olfactory cells of the pike, and suggested that the so-called olfactory hairs are really only their thickened proximal ends. But it is difficult to exclude the possibility (at least in our own preparations) that the "filaments" are nothing more than mucinous threads of adventitious origin which have attached themselves to the tips of the olfactory hairs. This, indeed, seems to be the most probable explanation of the appearance sometimes seen in protargol sections. The other variations mentioned above may be (at least in part) abnormal phenomena of degenerative origin. Our reason for such a conclusion is based on sections (tangential to the surface) through the olfactory mucosa of a normal rabbit (R286) in which the impregnation is usually successful and uniform. In these sections every rod which is traced to the surface ends in the same way, i.e. in a small terminal swelling from the upper circular margin of which the olfactory hairs diverge in stellate fashion (Figs. 7 and 9). The hairs usually do not stain as deeply as the olfactory rods. Counts made on the tangential sections show that the number of hairs at the distal end of each sensory cell is usually 10-12, and in some instances there may be as many as 13 or 14 . In other stellate formations there seem to be fewer, but in these cases there are often obvious gaps in the radial series which are apparently due to the displacement of some of the fine hairs so that they cannot be easily defined. It thus appears that in the rabbit the number of hairs considerably exceeds that commonly given for mammals, e.g. 5-6 in man (von Brunn, 1892; Kallius, 1905) or 5-8 in the pig (Alcock, 1910).

The only difference to be noted in these stellate formations is one of size, their total diameter varying from $4 \mu$ to $7 \mu$. In the large formations the olfactory hairs are coarser and stain more heavily. It has not been possible to establish that there is any definite pattern in the distribution of stellate formations of different sizes. In general the olfactory 
hairs of adjacent receptors do not overlap with one another, though they may be close enough to come into contact. They project up definitely beyond the distal margins of the supporting cells and thus lie free within the mucinous film which covers the olfactory epithelium during life.

It had been noted above that in different preparations (even though these had been fixed and stained by the same technique) the terminal swellings show some variation in size. It now seems clear that this is due to the varying extent to which the olfactory hairs become clumped together from their base upwards. Thus, to continue our floral simile, they may be widely splayed like the petals of an ox-eye daisy (in which case they lie almost flat on the surface of the free extremities of the supporting cells), or they may diverge only in their distal portion like the petals of a bluebell, or in some cases (Fig. 2) they may be grouped together like the closed petals of a tulip. In the last case, the clumped hairs give the appearance of an unusually large terminal swelling. Whether these are normal variations which occur in life, it is not yet possible to state.

At the distal extremities, the olfactory rods are evenly disposed over the surface of the olfactory epithelium (except at the points where the ducts of the olfactory glands of Bowman break through). At a deeper level they are disposed in a hexagonal pattern between the supporting cells, each of the latter having 6 to 10 rods applied to its surface (Fig. 10). On the basis of counts made on tangential sections, it is estimated that, in the rabbit's olfactory epithelium, the density of olfactory rods is of the order of 150,000 per sq. mm.

Because of their fineness, the proximal processes of the olfactory sensory cells, extending from the cell bodies to the basement membrane, are exceedingly difficult to demonstrate, and when they are demonstrable to the eye with the use of an oilimmersion lens, they are very difficult to reproduce convincingly in a photograph. They are illustrated in the microphotograph shown in Fig. 8, which has been partly retouched. The processes pass vertically down towards the basement membrane and, as they approach the latter, a number converge to form a small fasciculus of olfactory nerve fibres. These fasciculi, which are formed at fairly regular intervals immediately beneath the epithelium, join the main longitudinal fasciculi which are directed upwards and backwards towards the cribriform plate (Fig. 6). So far as can be determined from our material, the olfactory fibres maintain their individuality from their origin in the cell bodies of the sensory cells to their termination in the olfactory bulb; in other words, each nerve fibre serves only one receptor. Further, unlike sensory surfaces such as the skin, there is practically no overlap in the epithelial distribution of different fasciculi and there is no subepithelial plexus. Indeed, our material also confirms the statement made by Read (1908) that the main olfactory fasciculi do not anastomose to form an interweaving plexus in the olfactory cavity as is commonly represented to be the case in text-book illustrations. On the contrary, they run in parallel formation, following a straight course upwards and backwards to the cribriform plate, and any interchange of fibres between adjacent fasciculi appears to be quite exceptional (Fig. 11). Thus it may be said that from each localized area of the olfactory mucosa the olfactory nerve fibres proceed by the shortest and most direct route to reach the intracranial cavity. On the other hand, as soon as they have pierced the cribriform plate they immediately enter into the formation of a most complicated and intricate plexus on the surface of the olfactory bulb, and it is clear from the study of silver sections that the fibres of all the fasciculi here undergo a complete rearrangement before the latter are sorted out into the terminal fasciculi which enter the glomeruli. The possible significance of this "sorting out" is discussed later in reference to the experimental studies.

\section{Retrograde Degeneration of the Olfactory Epithelium}

Previous studies of the effect on the olfactory epithelium of destruction of the olfactory bulb, or of section of the olfactory nerves, have led to equivocal and sometimes conflicting results so far as mammals are concerned. Baginsky (1894) reported that section of the olfactory nerves in young rabbits led to atrophy of the entire olfactory mucosa (including both the epithelial and the subepithelial tissues), the degree of atrophy being more severe in the long-term experiments (up to 68 days). However, he considered the possibility that these results may have been, at least in part, due to interference with the vascular supply. Lustig (1884) destroyed one or both olfactory bulbs in 12 rabbits and examined the olfactory mucosa after intervals of 45-65 days. He found that all the cell elements of the epithelium underwent degeneration (that is, supporting and basal cells as well as sensory cells). It seems not improbable that the results reported by Baginsky and Lustig may both be vitiated by the fact that some of the changes observed in the olfactory mucosa were due to the rhinitis which not uncommonly affects laboratory animals. Takata (1929) expressed the opinion that destruction of the olfactory bulb in rats is not followed by changes in the olfactory region so long as the vascular supply to the nasal cavity is not interfered with. On the other hand, he found that trauma of a large number of the olfactory fibres in the immediate neighbourhood of the cribriform plate led to degeneration of the olfactory sensory cells. He also stated that, in regions of severe degeneration, the olfactory epithelium becomes replaced by the type of ciliated epithelium characteristic of the respiratory region of the nasal cavity. Here again, however, the histological picture may have been obscured by inflammatory changes, for, according to Nagahara (1940), such metaplasia may occur in chronic rhinitis. An examination of the microphotographs reproduced in Takata's paper makes it quite evident that his histological material was of very poor quality and 
that some of his experimental animals actually were suffering from quite severe rhinitis. Nagahara studied the effect of. olfactory bulb ablation and olfactory nerve section in mice, and he noted that such lesions were followed by a rapid degeneration of the olfactory epithelium involving most of the olfactory cells. But he states that, as soon as three days after the operation, the basal cells start to proliferate by mitotic division, and in approximately 90 days the regeneration of the olfactory epithelium is complete. From the regenerating cells, the central processes first appear, and later the peripheral processes. The centripetal growth of the regenerating axons finally leads to the establishment of new endings in glomerular formations in the -olfactory bulb. Nagahara also affirms that the presence of the olfactory bulb is not necessary for the regeneration of the olfactory cells and their processes, for in this case regenerating olfactory nerve fibres still grow out from the olfactory mucosa. In anticipation of the discussion of our own experimental studies, it may be said that the latter provided no evidence of such a regenerative process, and it is possible that Nagahara may have been misled partly by the incompleteness of his lesions and partly by the fact that pathological conditions affecting both the olfactory bulb and mucosa (which might simulate repair phenomena) are by no means uncommon in laboratory mice.

The effect of total ablation of the olfactory bulb.In a number of rabbits the right olfactory bulb was removed, and the animals killed at intervals ranging from twelve hours to eight weeks after the operation. The changes observed in the olfactory epithelium are as follows.

After twenty-four hours degeneration is very distinct (Figs. 12 to 15). The total thickness of the epithelium already shows a reduction, and the nuclei of the sensory cells are relatively fewer. Many of the nuclei which remain show various stages of pyknosis and karyorrhexis, and, in hæmatoxylin sections, deeply staining granules of nuclear débris are seen scattered in the intercellular spaces of the epithelium. The olfactory rods are distorted and frequently show varicose swellings, and, for the most part, the terminal swellings and olfactory hairs have undergone disintegration. The proximal processes of the sensory cells which remain tend to take on a darker stain with protargol, and the basement membrane of the whole epithelium has become more sharply defined than in the normal mucosa.

After 48 hours (Fig. 16) the degenerative changes. are much more marked. The whole epithelium has shrunk to approximately two-thirds of its normal depth and the majority of the nuclei of the sensory cells have now undergone disintegration. The products of the disintegration, in the form of nuclear débris and eosinophil granules, are partly to be seen in intercellular spaces, but a great deal has now been taken up into the cytoplasm of the supporting cells, and in many cases is contained there within large vacuoles. Sometimes also (but much less frequently) particles of débris may be found in a basal cell. It is clear from the histological picture that the supporting cells of the olfactory epithelium play a significant part in the phagocytosis of the products of degeneration of the olfactory sensory cells. Indeed, it is doubtful whether the removal of the débris involves the activity of any mobile elements of extraneous origin such as macrophages. A careful search has failed to show any indubitable macrophages in the olfactory epithelium at the height of retrograde degeneration (provided no infection is present), though occasionally a cell is seen in the basal layers which may have such an origin. However, it has not been found possible to decide with certainty whether such cells are not simply basal cells of the epithelium which have taken up some of the cellular débris. In view of Nagahara's statement that mitotic activity is very pronounced in the basal cells a few days after destruction of the olfactory bulb in mice, special attention has been given to this in the study of our histological material. Mitoses are very occasionally seen, but they are so rare that they can hardly be regarded as significant for a true regenerative process.

In an experiment in which the olfactory bulb had been removed three days before death, the degree of atrophy of the olfactory epithelium was found to be very similar to that just described in the fortyeight hours' material (Fig. 17).

After one week, the great majority of the olfactory cells have completely degenerated, and much of theo cellular débris resulting from this degeneration has now disappeared. The few olfactory rods whick remain are beaded and broken up into fusiform ${ }^{+}$ segments (Fig. 18). No fibrillary structure is evident in these remnants.

In the eight weeks' specimen, retrograde degeneration of the sensory elements is already complete (from other material we have reason to suppose that it is actually completed earlier-between two and three weeks after ablation of the olfactory bulb). The olfactory epithelium is reduced to practically half its normal thickness and now consists entirely of supporting and basal cells (Fig. 19). No sensory cells remain. The supporting cells retain their original morphological characters more or less unchanged (except that their infra-nuclear portion has shrunk to less than half the normal length), and they show no tendency to become transformed into other types of cell; nor do they develop cilia at their free extremities as has been reported by Takata (1929). All the olfactory glands of Bowman have undergone distinct atrophy; their cells are shrunken and irregular in outline, and they stain feebly with eosin. The fasciculi of the olfactory nerves in the submucosa show some degree of fibrosis. On the other hand, at no time up to eight weeks do these fasciculi show any proliferation of the Schwann nuclei (as might perhaps be anticipated to occur if there is any attempt at regeneration).

The effect of partial lesions of the olfactory bulb.In a series of experiments a portion only of the olfactory bulb of one side was excised in order to 
note the effect of such a partial lesion on the olfactory epithelium. The bulb was exposed in the usual way, and a varying amount removed. The proportional extent of the ablation was estimated approximately at the time of operation by direct inspection, and by naked-eye examination after death. However, the remains of the bulb were not serially sectioned for microscopic study, and thus in no case could the possibility be excluded that the actual lesion was rather more extensive than had been intended, as the result of local trauma and hæmorrhage. In all the experiments, the animals were killed seven days after the operation.

In three rabbits approximately half the bulb was removed, in two the rostral half and in one animal the upper or dorsal half. In all cases the ensuing atrophy of the olfactory epithelium was found to be spread over all the septal mucosa, and a rough count of the nuclei of the sensory cells shows that approximately half of these cells had disappeared. There is a corresponding thinning out of the olfactory rods (Fig. 21), and this thinning out also appears to be evenly spread over the septal epithelium. In another experiment in which approximately the rostral two-thirds of the bulb were removed, the ensuing atrophy of the olfactory epithelium was found to be more severe in degree (see Fig. 22). But in this case rather more than two-thirds of the sensory elements in the olfactory epithelium have undergone total atrophy, which may well be due to the fact that the effects of the lesion were somewhat more severe than had been intended. It should again be noted, however, that the atrophy is spread evenly over the septal mucosa. Lastly, in one experiment, approximately the rostral third of the bulb was removed at operation, and in this case again, although the thinning out of the sensory elements is rather greater than had been anticipated (presumably because of the fact that the effects of the lesion were more severe than had been intended), it corresponds roughly to the extent of the lesion.

In the course of the study of retrograde degeneration in the olfactory mucosa of mice, complete serial sections were prepared through the nasal cavity and olfactory bulbs of a supposedly normal animal, after decalcification and staining with a modified Bielschowsky's method. In this specimen, however, it was found that a localized part of the bulb had undergone atrophy (presumably as the result either of a development defect or of some infective process), thus providing further material for the study of the effects on the olfactory epithelium of a partial lesion of the bulb. The atrophy had involved the glomeruli and external plexiform layer of the bulb mainly over its dorsal, lateral, and ventral surfaces. The olfactory epithelium on the affected side is shrunk to a little less than two-thirds of the thickness of the epithelium on the opposite normal side, and the olfactory sensory cells are reduced to approximately one-third of their normal number. This partial atrophy of the olfactory receptor cells, it should again be noted, is evenly spread over the whole extent of the olfactory mucosa. It may thus be inferred that the normal glomeruli which remain on the medial surface of the bulb receive some olfactory fibres from the entire area of the olfactory epithelium. This specimen is of particular interest since it confirms the results of the experimental studies in rabbits and justifies the assumption that, in these studies, the septal mucosa may be taken as a representative sample of the whole olfactory area.

\section{Discussion}

Our experiments have demonstrated that partial or complete ablation of the olfactory bulb gives rise to a rapid degeneration of the olfactory epithelium. If care is taken to exclude all material in which there is any sign of rhinitis, the evidence is quite clear that the immediate degeneration involves only the sensory elements of the epithelium. In twentyfour hours many of these are already in process of disintegration, and by the end of a week most have disappeared altogether. The process of atrophy appears at first to be a simple autolysis, for we have found no clear evidence of phagocytic agents invading the epithelium. The fragments of the disintegrated nuclei of the sensory cells at the end of 24 hours are seen lying free in the intercellular spaces of the epithelium. By 48 hours, however, much of the débris has been collected in large vacuoles formed within the cytoplasm of the supporting cells. The latter thus appear to play a significant part in the removal of the products of degeneration. In some experiments, after removal of the olfaciory bulb a few sensory cells may persist throughout the epithelium. This is certainly due to the fact that in these cases the ablation of the bulb was not total, for the subsequent histological examination of stumps left after apparently total ablations showed that small portions of the bulb may not infrequently be left behind in the region where it meets the olfactory peduncle. This is of some importance in the consideration of the statement by Nagahara that rapid regeneration of the olfactory epithelium occurs in the mouse, for it seems possible that his " regenerated " elements may have been original sensory cells left behind as the result of an incomplete destruction of the bulb. However, he also reported that active mitotic proliferation of the basal cells of the olfactory epithelium was to be observed a few days after the operation. In our own experiments a careful search has failed to show any significant evidence of such mitotic activity; nor, indeed, have we found any evidence of a regenerative process up to eight weeks after removal of the bulb. After such an interval, the olfactory epithelium consists only of supporting cells and basal cells, and the olfactory fasciculi in the submucosa have undergone some fibrosis with no indication of any Schwann cell activity. It remains possible, of course, that the epithelium of the mouse possesses a regenerative capacity not found in the rabbit.

The rapidity of the epithelial degeneration in 
these experiments suggests the possibility that it may be due to an interference with the vascular supply of the olfactory mucosa and, as already noted, this has been put forward in explanation of the results recorded by previous workers. The vessels involved would presumably be the ethmoidal arteries, though their extradural position should safeguard them from injury in a careful ablation of the olfactory bulb. However, so far as our experiments are concerned, the possibility can be excluded for the following reasons. In the first place, the immediate degenerative process in the olfactory mucosa only affects the sensory cells; the supporting and basal cells of the epithelium and the subepithelial tissues remain unchanged. Secondly, partial lesions of the olfactory bulb are followed by an even thinning-out of sensory cells throughout the septal epithelium, and not by circumscribed changes in local vascular territories. Thirdly, removal of the dorsal half of the bulb (which involves no interference with the immediate neighbourhood of the cribriform plate) is also followed by a partial atrophy of olfactory cells. Lastly, in order to study directly the effect of unilateral ablation of the bulb on the vascularity of the olfactory mucosa, in one rabbit $6 \mathrm{c} . \mathrm{cm}$. of a 4 per cent. solution of bromophenol blue was injected into the ear vein a few minutes after the operation and the animal was killed ten minutes later. By this time most of the tissues normally supplied with blood are stained an intense blue, and in this particular experiment the mucous membrane in both sides of the nasal cavity was stained with equal intensity. Thus it seems clear that the degeneration of the sensory elements of the olfactory epithelium is a true retrograde degeneration.

If the septal mucosa may be regarded as representative of the olfactory mucosa as a whole, it can be stated that fractional removal of the olfactory bulb is followed, not by a complete atrophy of the sensory elements limited to a corresponding area of the mucosa, but to a general thinning-out of the sensory cells over the entire mucosa. This generalization was confirmed in the study of silver sections of the whole of the olfactory area in a mouse in which a partial atrophy of unknown origin was found incidentally in one olfactory bulb. While our data do not permit of an accurate quantitative assessment, the results of six experiments permit the statement that the degree of thinning-out of the olfactory sensory cells is approximately proportional to the amount of the olfactory bulb which is destroyed. The immediate significance of the intricate plexus formed by the olfactory nerve fasciculi after piercing the cribriform plate is now made apparent, for it is clear that it provides for a sorting out of the fibres in the fasciculi in such a way that each local area of the olfactory epithelium is projected on to all parts of the olfactory bulb. The further significance of the sorting out remains to be determined. It seems difficult to explain, however, except on the basis of the segregation of fibres conveying impulses related to different types of olfactory stimulation. If olfactory discrimination is ultimately dependent on peripheral analysers in the form of different olfactory receptors responsive to different types of stimulus (analogous to the peripheral analysing mechanisms in the retina or cochlea), it must be assumed that the olfactory fibres derived from each type of sensory cell require to be segregated so as to permit of some form of localization in their projection on the olfactory centres of the brain. We have noted that in our preparations the terminal swellings of the olfactory rods, together with the olfactory hairs, show certain morphological variations in form and size, but these variations show no regularity in their distribution which might suggest a relationship to functional types of receptor. On the other hand, the sensory cells all over the olfactory mucosa vary greatly in the length $(20 \mu-90 \mu)$ of their distal processes (the olfactory rods), and the idea suggests itself that such a spectrum of rod lengths might provide a possible basis for the analysis of olfactory stimuli of different kinds. However, we have not been able to determine that partial destruction of the olfactory bulb leads to a selective atrophy of olfactory rods of any particular length, though it remains possible that much more localized lesions in the bulb might demonstrate such a relationship. If there is any form of localization within the olfactory bulb in the sense that olfactory receptors related to different kinds of olfactory stimuli are projected on to dif ferent glomeruli within the bulb, it might be expected that partial lesions of the bulbs (bilaterally syme metrical in extent) would lead to a partial anosmia of a selective type. Hitherto, however, there is no evidence for such a supposition as far as we are aware, possibly because such circumscribed lesions only very rarely become available for study.

\section{Summary}

1. In the rabbit, the olfactory receptors form distally small terminal swellings from each of which 10-12 olfactory hairs commonly arise. The variations in the appearance of the terminal swellings and the hairs are discussed.

2. The density of olfactory receptors in the rabbit is estimated to be of the order of 150,000 per sq. mm.

3. There is no overlapping in the distribution within the olfactory epithelium of fasciculi of olfactory nerve fibres, nor is there a subepithelial plexus.

4. The main fasciculi of the olfactory nerves proceed in parallel bundles by the shortest and most direct route to the cribriform plate of the ethmoid, and there is no plexiform arrangement within the nasal cavity.

5. As soon as they have pierced the cribriform plate, the olfactory nerve fasciculi enter into the formation of a most intricate plexus.

6. Total ablation of the olfactory bulb is followed by a very rapid retrograde degeneration in the olfactory epithelium which is already well advanced twenty-four hours later, and within one week most of the sensory elements have disappeared.

7. The supporting cells of the olfactory epithelium 
play a significant part in the phagocytosis of the products of degeneration of the sensory cells.

8. No evidence of regeneration is apparent up to eight weeks after ablation of the olfactory bulb.

9. Partial ablation of the olfactory bulb is followed by a general thinning-out of the olfactory sensory cells over all the olfactory area of the corresponding side. The degree of this thinning-out is approximately proportional to the size of the lesion.

10. It is inferred that olfactory fibres from each local area of the olfactory mucosa are distributed to all parts of the olfactory bulb. The significance of this type of projection is discussed.

We wish to express our gratitude to $\mathrm{Mr}$. E. Thompson for his expert assistance in the preparation of the histological material, and to Mr. W. Chesterman for his microphotographic skill.

\section{REFERENCES}

Alcock, N. (1910). Anat. Rec., 4, 123.

Baginsky, B. (1894). Virch. Arch., $137,389$.
Bodian, D. (1936). Anat. Rec., 65, 89.

Brunn, A. von (1875). Arch. mikr. Anat. 11, 468. (1892). Ibid., 39, 632.

Cajal, Ramon y. (1889). Gac. med. Catalana, 12, 6 (quoted by the same author in "Histologie du Système Nevreux", vol. 2. Paris, 1911).

Exner, S. (1872). Sitzung. K. Akad. Wiss., 65, 7.

Gehuchten, A. van (1890). La Cellule, 6, 393.

Grassi, B. and Castronuovo, A. (1889). Arch. mikr. Anat., 34, 385.

Jagodowski, K. P. (1901). Anat. Anz., 19, 257.

Kallius, E. (1905). "Handbuch der Anatomie des Menschen." Edited by Bardeleben. Vol. 5, 115, Fischer, Jena.

Kolmer, W. 1927). " Handbuch mikr. Anat." Edited by von Mollendörf. Vol. 3, teil 1, p. 192.

Lustig, A. (1884). Sitzung. Math-Naturwiss. Classe Kais. Akad. Wissen., 89, 119.

Nagahara, Y. (1940). Jap.J. med. Sci. (Sect. 5: Pathol.), $5,165$.

Read, E. A. (1908). Amer. J. Anat., 8, 17.

Stricht, O. van der (1909). Mém. Cour. Acad. Roy. Méd. Belg., 2nd Ser., 2, 20.

Takata, N. (1929). Arch. Ohren Nasen Kehlkopfh., 121, 31.

\section{EXPLANATION OF PLATES}

Except where otherwise mentioned, all the microphotographs are of sections stained with Bodian's protargol method.

\section{Plate I}

FIG. 1.-Distal processes of olfactory cells showing the olfactory rods, terminal swellings, and olfactory hairs. Note that the "double" appearance of the rods is due to the fact that the neurofibrillæ are situated peripherally so that the rods here appear to have a "tubular" structure. $\times 1800$.

FIG. 2.-Distal processes of olfactory cells showing the appearance produced by the clumping of the olfactory hairs. The terminal swellings of the olfactory rods are thereby made to appear unusually large. $\times 1800$.

FIG. 3.-Distal processes showing the terminal swellings and olfactory hairs. $\times 1500$.

FiG. 4.-Distal processes showing darkly staining endbulbs at the end of olfactory hairs-probably degenerative formations. $\times 1500$.

FIG. 5.-Distal processes of olfactory cells in which the terminal swellings and olfactory hairs show certain variations from their usual appearance, which may possibly be abnormal. $\times 1500$.

FIG. 6.-Section of the olfactory mucosa showing one of the main fasciculi of the olfactory nerves receiving accessions of fibres from the olfactory epithelium. $\times 84$.

Fig. 7.-Tangential section through the surface of the olfactory epithelium showing the olfactory hairs radiating from the terminal swellings of the olfactory rods. $\times 2300$.

FIG. 8.- Section of normal olfactory mucosa showing the proximal processes of the sensory cells passing through the basement membrane to form a fasciculus of olfactory nerve fibres. Since it proved impossible to bring all the proximal processes into focus simultaneously, this microphotograph has been slightly retouched in order to demonstrate them clearly. $\times 770$.

\section{Plate II}

Fig. 9.-Tangential section through the surface of the olfactory epithelium showing the olfactory hairs radiating in stellate fashion from the terminal swellings of the olfactory rods. Note the variation in size of these stellate formations. $\times 2000$.

FIG. 10.-Tangential section through the olfactory epithelium near the surface of the latter. The olfactory rods are seen disposed in a hexagonal pattern between the adjacent sides of the supporting cells. Towards the upper part of the microphotograph the level of the free extremities of the supporting cells is reached, and here the olfactory rods are more evenly dispersed. At the uppermost part of the microphotograph the actual surface of the mucosa is shown, and at this level are the stellate formations of olfactory hairs (not clearly visible at this magnification). $\times 600$.

FIG. 11.-Tangential section through the submucosa in the olfactory area of the nasal septum, showing the main fasciculi of the olfactory nerves passing in parallel formation and demonstrating the absence of the plexiform arrangement which is commonly depicted in diagrams. Between the fasciculi can be seen alveoli of the olfactory glands of Bowman. $\times 46$. 


\section{Plate III}

FIG. 12.-Section of normal olfactory epithelium, stained with hæmatoxylin and eosin. $\times 900$.

FIG. 13.-Section of the olfactory epithelium (stained with hæmatoxylin and eosin). 24 hours after total ablation of the olfactory bulb of the same side. Note, in comparison with the preceding figure (which is taken from the normal side of the same animal), the reduction in the total thickness of the epithelium and in the number of nuclei of sensory cells. The disintegration of some of these nuclei is also demonstrated. $\times 900$.

FIg. 14.-Section of normal olfactory epithelium, for comparison with succeeding figures. $\times 600$.

FIG. 15.-Section of the olfactory epithelium 24 hours after total ablation of the olfactory bulb of the same side. Note, in comparison with the preceding figure (which is taken from the unoperated side of the same animal), the reduction in the total thickness of the epithelium and in the number of nuclei of sensory cells, the distortion of the olfactory rods, the virtual disappearance of the terminal swellings, and the accentuation of the basement membrane. $\times 600$.

FIG. 16.-Section of the olfactory epithelium 48 hours after total ablation of the olfactory bulb of the same side. There is a further reduction in the total thickness of the epithelium, and many of the olfactory rods have disappeared. $\times 600$.

FIG. 17.-Section of the olfactory epithelium three days after total ablation of the olfactory bulb of the same side. Only a few olfactory rods now remain. $\times 600$.

FIG. 18.-Section of the olfactory epithelium one week after total ablation of the olfactory bulb. Most of the sensory. cells have disappeared, and the few remaining remnants of the rods are fragmented. This section is taken from material fixed in formolsaline, and is thus not directly comparable with the other microphotographs of this series, which are taken from material fixed in alcohol. $\times 600$.

FIG. 19.-Section of the olfactory epithelium eight weeks after total ablation of the olfactory bulb, stained with hæmatoxylin and eosin. All the sensory cells have disappeared and only the supporting and basal cells remain. $\times 600$.

FIG. 20.-Section of normal olfactory epithelium for comparison with the succeeding microphotographs. $\times 600$.

FIG. 21.-Section of the olfactory epithelium one week after ablation of half the olfactory bulb of one side. Note, in comparison with the preceding figure (which is taken from the unoperated side of the same animal), the reduction of the nuclei of the sensory cells to approximately half their normal number, and a corresponding thinning-out of the olfactory rods. $\times 600$.

FIG. 22.-Section of the olfactory epithelium one week after ablation of two-thirds of the olfactory bulb of the same side. There is a very marked reduction of the nuclei of the sensory cells and of the olfactory rods. $\times 600$. 


\section{Plate I}

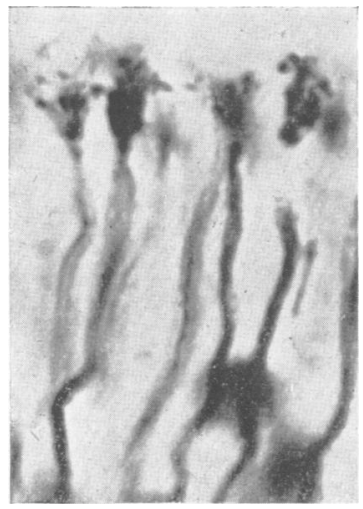

FIG. 1.

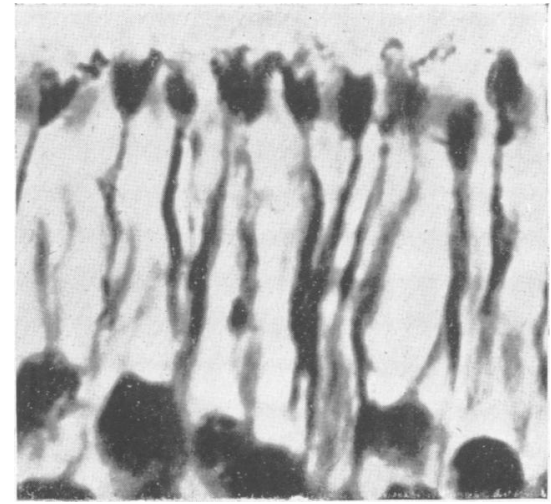

FIG. 2.

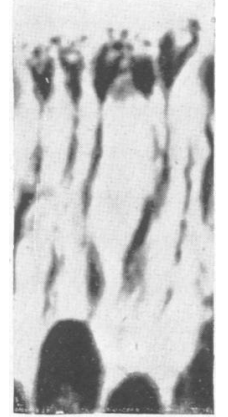

FIG. 3.

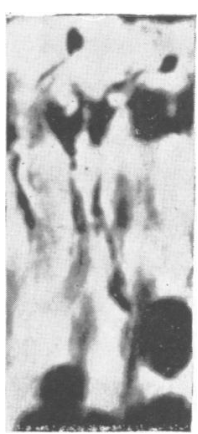

FIG. 4.
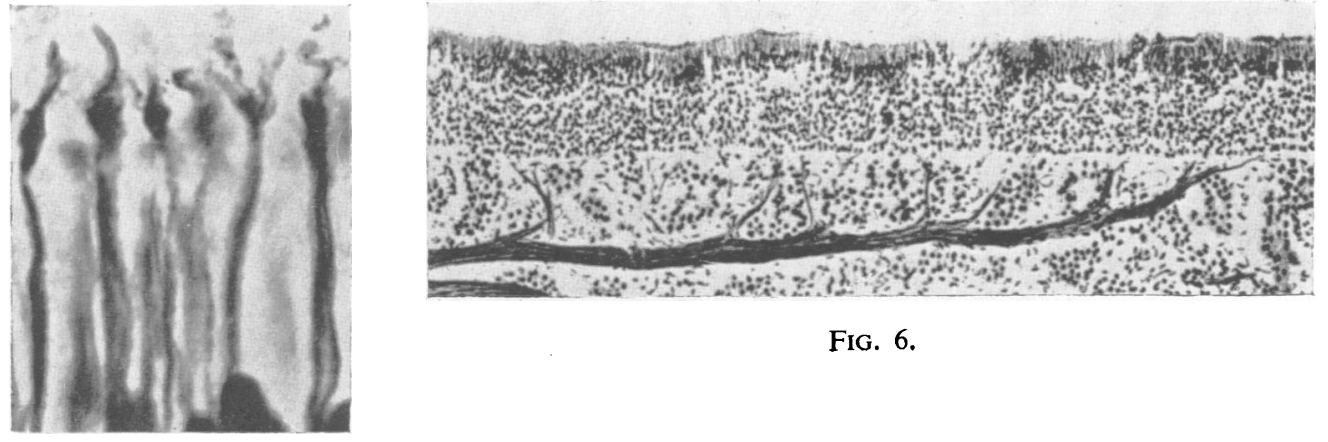

Fig. 6.

FIG. 5.



Fig. 7.

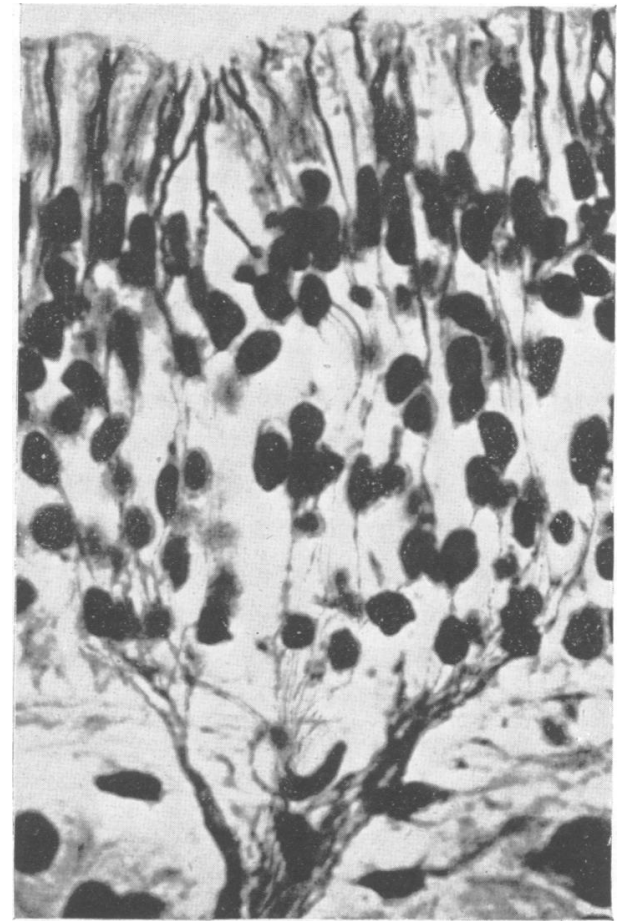

Fig. 8.

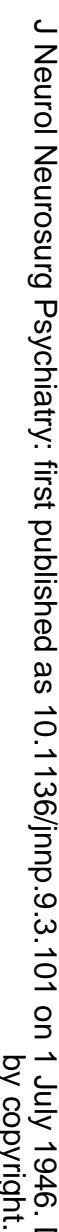

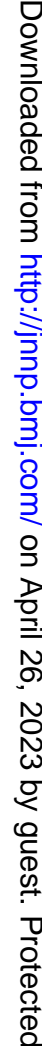


Plate II



FIG. 9.

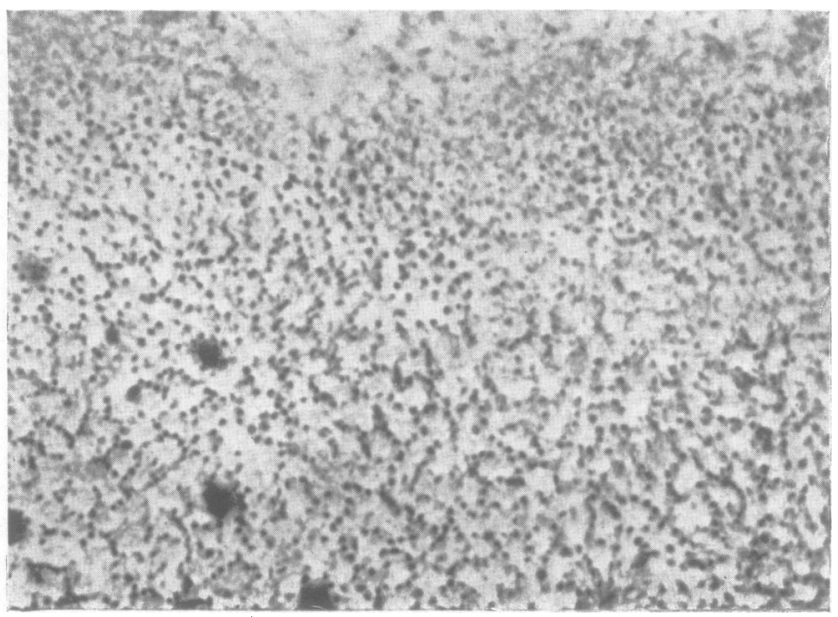

FIG. 10.

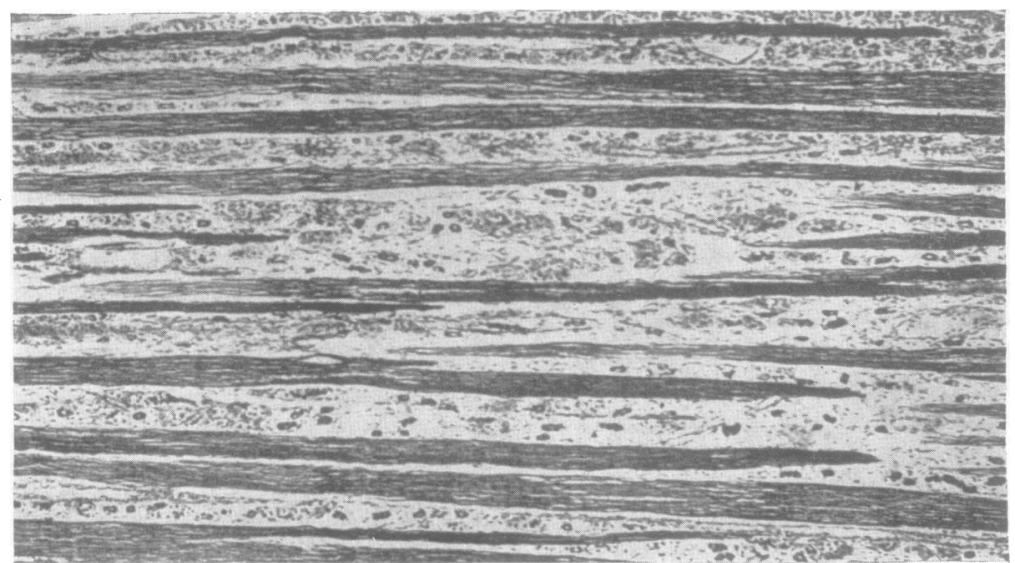

Fig. 11 . 
Plate III

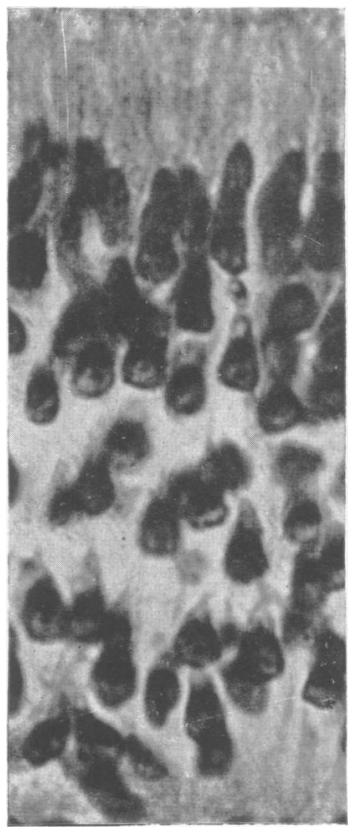

Fig. 12.

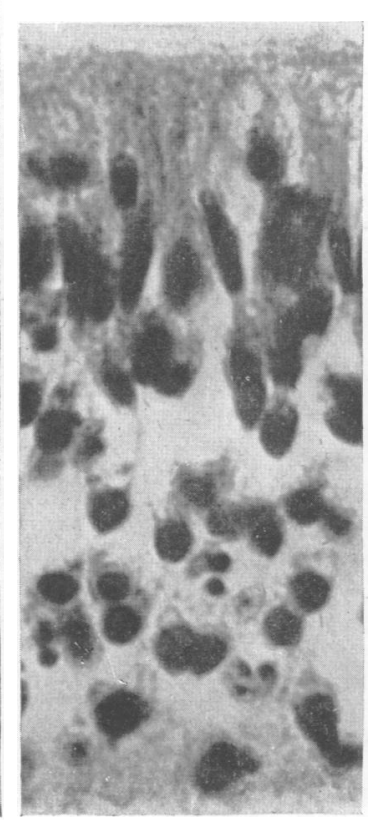

FIG. 13.

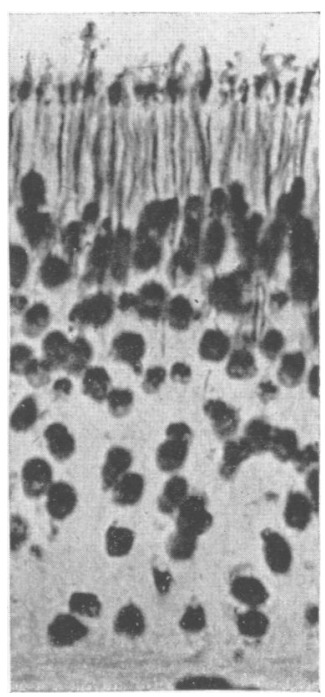

FIG. 14.

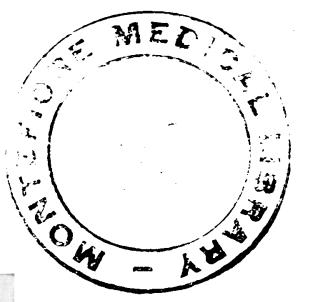

111

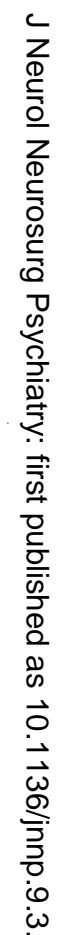

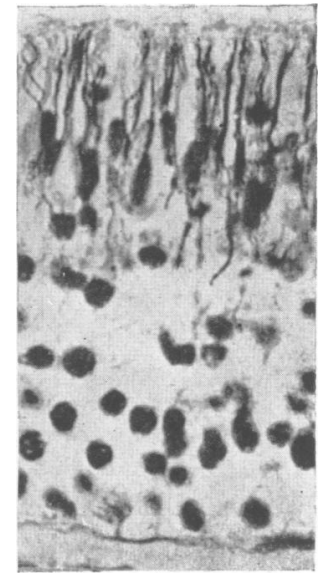

FIG. 15.

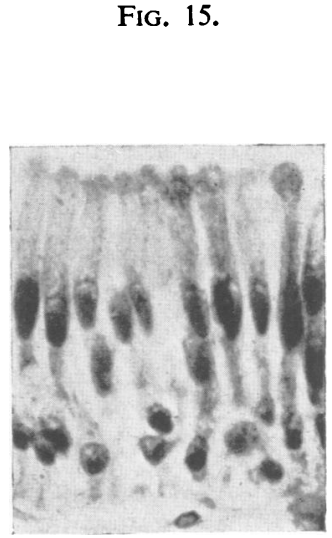

FIG. 19.

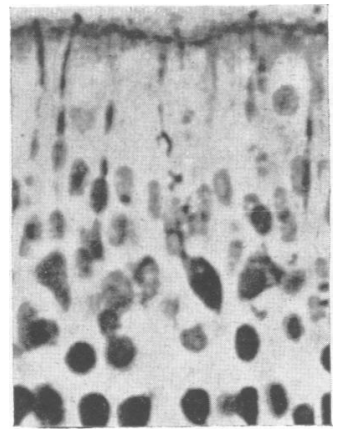

FIG. 18.
FIG. 17.

FIG. 16.

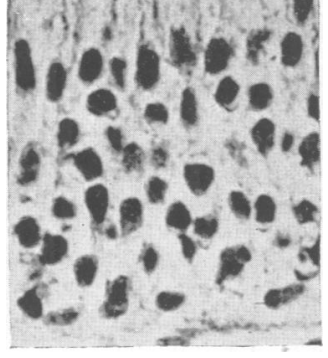

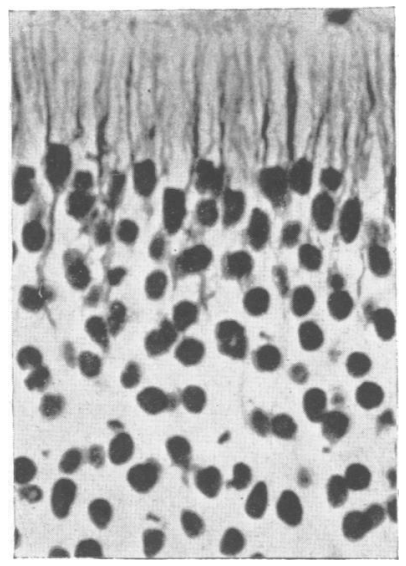

Fig. 21.

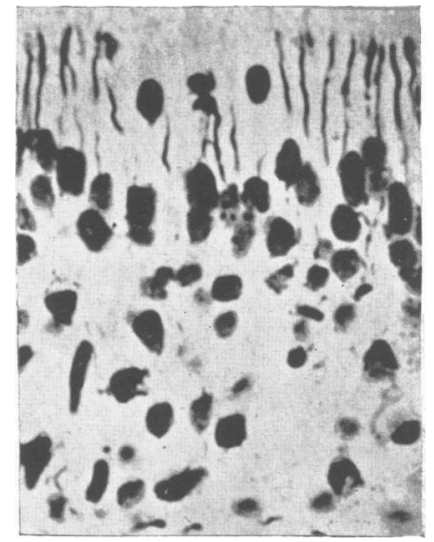

FIG. 22.

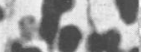

ire

- olege o dol ans Den

FIG. 20. 